\title{
Guide to strategic planning in critical care medicine
}

\author{
Kwadwo Kyeremanteng, Gianni D'Egidio * \\ University of Ottawa, Department of Medicine, Division of Critical Care, The Ottawa Hospital, Ottawa Ontario, Canada
}

Received: March 23, 2015

DOI: $10.5430 /$ jha.v4n3p93
Accepted: May 3, 2015

URL: http://dx.doi.org/10.5430/jha.v4n3p93

\begin{abstract}
Strategic planning is increasing in value. More organizations are implementing such strategies to help achieve their corporate goals. Strategic planning can help improve morale and satisfaction amongst staff, managers and stakeholders. It can help improve efficiency within the organization and ideally the quality of care as well. Most importantly, it helps an organization to focus and prioritize its goals therefore increasing its chances for success. Critical care medicine is a unique branch of medicine because of the high costs associated with care. It is reasonable to perceive that these costs will go up in the future. Our population is aging and our abilities to sustain life are constantly improving. ICU is also unique because it is associated with high stress for the patients, families, nurses, physicians and allied health professionals. Care is often associated with post-traumatic stress and burnout. For these reasons strategic planning is essential for critical care to thrive, provide good care for patients and to allow for efficient use of resources. There are several approaches to strategic planning. This article will look at the 10-step method described in Bryson's Strategic Planning for Public and Non-Profit Organizations and how it can apply to critical care medicine.
\end{abstract}

Key Words: Critical care, Strategic planning, Quality improvement, Hospital administration

\section{INTRODUCTION}

Strategic planning is seen as an opportunity for an organization to achieve its goals. Strategic planning can improve morale, satisfaction, and efficiency among employees and stakeholders. When used in a healthcare environment this may ultimately translate into improved care and decreased costs.

Critical care medicine is a resource intensive practice of medicine. One-to-one nursing, high tech machinery, and frequent biochemical and radiological imaging results in high costs of care. It is estimated that ICU costs represent $1 \%$ of GDP. ${ }^{[1]}$ In terms of hospital cost, it approaches $13 \% \cdot{ }^{[1]}$ It is reasonable to perceive that these costs will go up in the future. Our population is aging and our abilities to sustain life are constantly improving. For example, patients with severe sepsis and septic shock have had an improvement in mortality from $45 \%$ to roughly $20 \%$ over the course of 15 years. ${ }^{[2]}$
ICU is also unique because it is associated with high stress for patients, families, nurses, physicians and allied health professionals. Care is often associated with post-traumatic stress and burnout. ${ }^{[3]}$ For these reasons, strategic planning is essential for critical care to thrive and to provide good care for patients in an efficient manner.

There are several approaches to strategic planning. This article will look at the 10-step method described in Bryson's Strategic Planning for Public and Non-Profit Organizations and how it can apply to critical care medicine (see Table 1).

\section{THE 10-STEP METHOD}

2.1 Initiate and agree upon a strategic planning process An important initial step is determining the key stakeholders, groups and decision makers. Without the buy-in and support of the influential parties, it will be hard for the organization to accept change. For this reason, the key stakeholders need Canada.

*Correspondence: Gianni D’Egidio; Email: degidio.gianni@gmail.com; Address: 501 Smyth Road, K1H 8L6 Office, M2895, Ottawa Ontario, 
to understand the need for change and agree that strategic planning is the way to create said change. Without their support, there will be resistance and as a result failure. Key stakeholders are often familiar with the details of the organization and can help foresee potential obstacles and provide solutions to best achieve goals.

Table 1. 10-step method described in Bryson's Strategic Planning for Public and Non-Profit Organizations

1. Initiate and agree upon a strategic planning process

2. Identify organizational mandates

3. Clarify organizational mission and values

4. Assess the organization's external and internal environments to identify strengths, weaknesses, opportunities, and threats

5. Identify the strategies to manage these issues

6. Formulate strategies to manage these issues

7. Review and adopt the strategic plan

8. Establish an effective organizational vision

9. Develop an effective implementation process

10. Reassess strategies and the strategic planning process

Critical care is unique because there are numerous stakeholders. In terms of medical specialties, because ICU accepts patients from all parts of the hospital, several divisions are invested in the ICU. Anesthesia and general surgery are involved because many post-op patients are transferred for management. Many patients are transferred from the internal medicine service. Internal medicine may manage step-down beds, which can often unload the pressure from ICU. Numerous patients are admitted from the ER therefore ICU can impact their patient flow. There are multiple allied health teams entrenched in critical care. Physiotherapy, respiratory therapy, occupational therapy, speech language pathology and social work are all important and influential members of any ICU. The nursing staff account for the majority of the ICU workforce. A 32-bed ICU will have up to 200 nurses on their roster. Because of the high costs associated with care, hospital administration and regional health authorities are often invested in critical care issues. For any strategic planning initiative, each of these stakeholders needs to be considered.

Another important step is an agreement on the process. For this to happen there needs to be agreement on the following; value of strategic planning, who will be involved and what their roles will be, and the format and timing of reporting. Strategic planning coordination committee often facilitates this. This group can make decisions such as who will champion the initiative. They can establish the initial agreement and make decisions regarding final membership of the strategic planning committee.

Within critical care, the ideal champion would be the depart- ment chair. They sit on several committees at the departmental, hospital, and regional health authority level. They typically have a sense of the culture and the readiness for change at each level.

\subsection{Identify organizational mandates}

Understanding the formal and informal mandates within an organization will promote an understanding of the requirements, expectations, and constraints that may challenge a strategic plan. By clarifying the mandates, one avoids the perception of being constrained when constraints do not exist. Also, by knowing the regulations, one is less likely to violate them. ${ }^{[4]}$ This is another reason why ideally the department head should be leading the strategic planning. Often they have been part of the hospital for numerous years and have a sense of the formal or informal mandates.

\subsection{Clarify organizational mission and values}

An organization's mission statement helps clarify an organization's purpose. This can be an arduous process but is a key step regarding strategic planning. It can help guide the overall direction the organization would like to pursue. When determining a mission statement it can be helpful to determine the goals within the organization. In critical care, quality of patient care, appropriate allocation of resources, and meeting the needs of the public are often central themes.

\subsection{Assess the organization's external and internal envi- ronments to identify strengths, weaknesses, opportu- nities, and threats}

This is a key step in determining an organization's potential for growth and the limitations that may lie ahead. Essentially this will allow an organization to gain perspective on its overall position. When looking at critical care, external environment mostly pertains to funding. For example, medical emergency teams were established in Ontario in 2006. This involved an ICU physician, a dedicated respiratory therapist and nurse to deal with any critically ill patient being managed outside the ICU. The benefit of these teams is they may reduce ICU admissions. They may also deal with goals of care and DNR issues for patients that were poor ICU candidates. Overall, they would reduce ICU admissions and ideally reduce overall costs. ${ }^{[5]}$ The funding for these teams was roughly $\$ 2,000$ per day. Several hospitals sought out funding for medical emergency teams but the Ontario government limited them to hospitals of higher need. Assessment of the external environment would evaluate the chances of further funding or additional funding for those that do not have medical emergency teams.

Another method of evaluating the external environment is inviting public participation. Citizen participation has been 
well supported at multiple levels. ${ }^{[6]}$ This may be valuable in critical care medicine as well. This is another venue that would allow for further understanding of public needs.

Internal assessment evaluates the resources, current strategy, and performance of the organization. Resources for critical care comprise mostly of staffing and capacity issues. Based on hospital budgets, resources can be significantly decreased or increased.

Evaluating one's strengths and weaknesses allows the organization to see where they are thriving and where improvement can be made. SWOT analysis is a frequently used method to evaluate these elements. The following are the two methods used for SWOT analysis: "Organizational Highs, Lows, and Themes Exercise" and "Snow Card Technique". ${ }^{4]}$ The former uses SWOT with emphasis on looking at the organization's past before looking forward. The latter utilizes brainstorming exercises where ideas are grouped together based on common themes. Either method would be appropriate in the critical care setting.

\subsection{Identify the strategies to manage these issues}

Identifying strategic issues may be the most important step in strategic planning. There are four methods used for identifying strategic issues: the direct approach, the indirect approach, the goals approach, and the "vision of success" approach. ${ }^{[4]}$ The "vision of success" approach would be most applicable to critical-care medicine. Often with this approach decisions are based on its vision and typically are based on a method. Given the numerous stakeholders, this is likely the best strategy for critical care medicine.

It is also important to prioritize the issues. The main issues regarding prioritization are the following: evidence-based decision-making, incentives, physician involvement, public involvement and values. ${ }^{[7]}$ These concepts apply to critical care medicine at a macro level. For evidence-based decisionmaking, educational initiatives may be implemented to improve quality. This is often seen with ventilator associated pneumonia and central line infection prevention in the form of hand hygiene education. In terms of incentives, funding is often based on performance. For example, the funding of medical emergency teams may be reduced if ICU admissions are not decreasing. In terms of physician involvement, this is an important component to be able to create change. Without physician involvement, it is more difficult to achieve buy-in. As mentioned previously, public involvement has shown to be beneficial at numerous levels. In terms of values, not only is this important at a hospital level, but also at a health authority level. This often serves as a checkpoint in the priority setting process. ${ }^{[7]}$

Published by Sciedu Press

\subsection{Formulate strategies to manage these issues}

If the strategy is implemented correctly, it will effectively link the organization to its environment. As per Bryson, strategy is an extension of an organization's mission. There are two major approaches to strategic development: the five-step process and action oriented strategy-mapping process. The five step method asks the following questions:

- What are the practical methods to resolve the issues?

- What are the barriers to succeed?

- What proposals need to be followed to overcome the identified barriers?

- What actions need to be taken within the next 1-2 years?

- What specific steps must be taken in the next 6 months and who is responsible?

This was similar to the method used by the Canadian Patient Safety Institute (CPSI) to develop a scorecard for safe and effective patient care in the ICU. ${ }^{[8]}$ Their mandate was to improve patient safety within critical care. Essentially they established a scorecard for evaluation of patient care. They overcame barriers by getting buy-in from critical care staff from across the nation, such as department chairs. They acknowledged information technology was one of the largest barriers to success. A central web-based reporting system was proposed to provide all organizations with consistent and valid reports. This is an ongoing effort by CPSI but one of their specific steps in their aim for success is to increase the number of contributing ICUs.

\subsection{Review and adopt the strategic plan}

Influential decision-makers, internal and external stakeholders, and the strategic team typically will review the initial draft of the strategic plan. This is valuable because it will allow for modifications prior to presentation to the final decision-makers. The next step will be adaptation of the strategic plan. At this point the final decision-makers have agreed for implementation. The key to this step is that the strategic plan is fully endorsed by the organization and its leaders.

A simple strategy to prepare for this is to use a strategic plan tool. ${ }^{[9]}$ Bryson illustrates a tool that outlines how to review and adopt a strategic plan. This provides guidance to an organization on how they can adopt a strategic plan. They also discuss which stakeholders are likely to support or oppose their strategy and develop a plan to deal with the opposition. The tool also helps clarify the process of what will be done, who will do it, what will be the timeline and how will it be done. 


\subsection{Establish an effective organizational vision}

An organization's vision helps outline what the organization wants to be. This essentially is the end goal of strategic planning. In order to develop a vision the organization must determine its purpose, which should be concise and inspiring. The purpose should then be communicated throughout the organization. Ultimately, when the vision is complete it should be able to guide decisions within the organization. For example, The Cleveland Clinic's vision statement is "Striving to be the world's leader in patient experience, clinical outcomes, research and education." ${ }^{[10]}$ Basically, the vision statement should represent a realistic goal the organization intends to achieve.

\subsection{Develop an effective implementation process}

For implementation to be successful, an organization must be able to manage change. Often these processes are met with high levels of resistance but this must be overcome for implementation to be effective. Often this can be overcome if the changes are easy and rapidly implemented. Communication of responsibilities and who is accountable are also key components. Overall, an investment in communication will pay dividends. The time required for implementation should not be prolonged. One does not want to lose momentum. ${ }^{[11]}$ If implementation is simple consider using the direct method. In situations where implementation is more complicated or associated with a difficult situation, stage implementation may be more appropriate. Because of the numerous staff of the complexity of issues within critical care medicine, a staged approach would likely be more beneficial for most strategic planning implementation.
For example, many ICUs are supporting early mobilization of their ventilated patients. This process involves reduction of sedation, training of nurses, respiratory therapists and physiotherapists, ensuring up to date sedation and analgesia scales. Due to the complexity of the strategy, a staged approach would allow for more effective implementation.

\subsection{Reassess strategies and the strategic planning pro- cess}

The following are strategic management systems approaches used to evaluate strategic planning: integrated units of management, strategic issues management, contract, collaboration, portfolio management and benchmark. Ideally benchmark approach would be ideal for critical care medicine. Essentially this approach involves setting goals based on historical results or established evidence, then devising plans to be able to surpass those levels. For example, the benchmark for central line infection rates is 0.5 infections per 1,000 central line days. ${ }^{[12]}$ If these goals are not being met, the overall strategies need to be reassessed. These may lead to strategy change or strategy termination.

\section{CONClusion}

Strategic planning poses many challenges but if they are overcome, they are likely to pay dividends. Strategic planning is important at multiple levels within the healthcare system and this holds true for critical care. In an era where the population is aging and resources are limited, strategic planning is paramount to establish sustainability. As one can see, using the ten-step approach facilitates strategic planning and is useful for critical care medicine.

\section{REFERENCES}

[1] Halpern NA, Pastores SM, Greenstein RJ. Critical care medicine in the United States 1985-2000: an analysis of bed numbers, use, and costs. Crit Care Med. 2004; 32: 1254-1259. PMid: 15187502. http: //dx.doi.org/10.1097/01.CCM.0000128577.31689.4C

[2] Mayr VD, Dünser MW, Greil V, et al. Causes of death and determinants of outcome in critically ill patients. Crit Care. 2006; 10: 154 PMid: 17083735. http://dx.doi.org/10.1186/cc5086

[3] Jackson JC, Hart RP, Gordon SM, et al. Post-traumatic stress disorder and post-traumatic stress symptoms following critical illness in medical intensive care unit patients: assessing the magnitude of the problem. Crit Care. 2007; 11(1): 27. PMid: 17316451. http://dx.doi.org/10.1186/cc5707

[4] Bryson J. Strategic Planning for Public and Non-Profit Organizations: A Guide to Strengthening and Sustaining Organizational Achievement. San Francisco: Jossey-Bass; 2011.

[5] Goldhill DR, Worthington L, Mulcahy A, et al. The patient-at-risk team: identifying and managing seriously ill ward patients. Anesthesia. 1999; 54: 853-860. http://dx.doi.org/10.1046/j.136 5-2044.1999.00996.x
[6] Pivik JR. Practical Strategies for Facilitating Meaningful Citizen Involvement in Health Planning. Discussion Paper 23. Commission on the Future of Health Care in Canada. 2002.

[7] Mitton C, Patten S, Donaldson C, et al. Priority-Setting in Health Authorities: Moving beyond the Barriers The Calgary Experience. Healthcare Quarterly. 2005; 8(3): 49-55. http://dx.doi .org/10. 12927 /hcq. . 17154

[8] Martin C. Critical Care Vital Signs Monitor: A scorecard for safe and effective patient care in the ICU. Canadian Patient Safety Institute. 2009; 1-87.

[9] Bryson J, Alston FK. Creating and Implementing Your Strategic Plan, 2nd Edition. JoseyBass; 2004.

[10] Available from: http://my.clevelandclinic.org/aboutclev elandclinic/overview/whoweare/missionvisionvalues. Retrived 26/04/15.

[11] Hrebiniak LG. Obstacles to Effective Strategy Implementation. Organizational Dynamics. 2006; 35(1): 12-31. http://dx.doi .org/1 $0.1016 / j$. orgdyn. 2005.12.001

[12] Available from: www.health.gov.on.ca/en/pro/programs/e cfa/.../appendix_c_2013.13.pdfpdf. Retrieved 30/06/13. 